\title{
Investigating the necessity of computed tomographic scans in children with headaches: a retrospective review
}

\author{
Rohit Gandhi, $\mathrm{HBA}^{*{ }^{\dagger}}$; Evan Cole Lewis, MD*; Jeanette W. Evans, BSc*${ }^{*}$; Erick Sell, MD*
}

\section{ABSTRACT}

Objective: Headaches are a common problem in the pediatric population. In 2002, the American Academy of Neurology (AAN) developed guidelines on neuroimaging for patients presenting with headache. Our objective was to determine the frequency of computed tomographic (CT) scanning ordered by a range of medical practitioners for pediatric patients presenting with primary headache.

Methods: A retrospective chart review was conducted at the Children's Hospital of Eastern Ontario (CHEO), a tertiary care centre in Ontario. One hundred fifty-one records of patients referred to the outpatient neurology clinic at CHEO with "headache" or "migraine" as the primary complaint from 2004 to 2009 were randomly selected. Ninety-nine patients with normal neurologic examinations were ultimately included.

Results: Thirty-four patients $(34 \% ; 95 \% \mathrm{Cl} 25-45)$ had undergone CT scanning. None of the 34 CT scans $10 \%$; $95 \% \mathrm{Cl} \mathrm{0-10)} \mathrm{showed} \mathrm{significant} \mathrm{findings,} \mathrm{and} \mathrm{none} \mathrm{changed}$ the headache diagnosis or management. Eleven (32\%) of the CT scans were ordered by CHEO neurologists, 15 (44\%) by community physicians, and $8(24 \%)$ by CHEO emergency physicians.

Conclusion: A high proportion of children presenting with primary headaches and a normal neurologic examination undergo CT scanning, despite well-established AAN guidelines regarding neuroimaging. Most of these CT scans do not appear to alter diagnosis and management. A variety of non-evidencebased factors may be encouraging physicians to overinvestigate this population and, as a result, increasing the risk of adverse events due to radiation exposure. Implementing initiatives at a site-based level that promote the use of established guidelines before performing CT scanning in this population may be beneficial.

\section{RÉSUMÉ}

Objectif: Les céphalées sont un problème fréquent chez les enfants. En 2002, I'American Academy of Neurology (AAN) a élaboré des lignes de conduite sur la neuro-imagerie chez les patients souffrant de céphalées. L'étude visait à déterminer la fréquence des demandes de tomodensitométrie (TDM) faites par différents types de médecins praticiens en pédiatrie chez les enfants souffrant de céphalées primitives.

Méthode: Nous avons procédé à un examen rétrospectif de dossiers au Centre hospitalier pour enfants de l'est de I'Ontario (CHEO), un centre de soins tertiaires, en Ontario. Cent cinquante et un dossiers de patients dirigés au service de consultation externe en neurologie, au CHEO, de 2004 à 2009, pour des "céphalées" ou des "migraines" qui constituaient le principal motif de consultation, ont été choisis au hasard. À cela se sont ajoutés 99 patients ayant un examen neurologique normal.

Résultats: Trente-quatre patients (34\%; IC à 95\%: 25-45) ont subi une TDM. Dans aucun cas (0\%; IC à 95\%: 0-10), I'examen n'a révélé d'anomalies importantes ni changé le diagnostic de céphalée ou la prise en charge. Onze (32\%) examens par TDM ont été demandés par des neurologues, au CHEO; 15 $(44 \%)$, par des médecins de ville; et 8 (24\%) par des urgentologues, au CHEO.

Conclusions: Une forte proportion d'enfants souffrant de céphalées primitives et ayant un examen neurologique normal sont soumis à un examen par TDM, malgré les lignes de conduite bien établies de I'AAN en ce qui concerne le recours à la neuro-imagerie. Dans la plupart des cas, la TDM ne semble pas changer le diagnostic ou la prise en charge. Différents facteurs non fondés sur des données probantes peuvent inciter les médecins à explorer à l'excès la population en question, ce qui a pour effet d'accroître le risque d'événement indésirable lié à l'exposition au rayonnement. La mise en œuvre d'initiatives, dans les hôpitaux mêmes, favorisant l'application des lignes de conduite déjà établies avant le recours à la TDM dans cette population pourrait se révéler avantageuse.

Keywords: computed tomographic (CT) scan, headache, neurology, pediatric

From the *Department of Pediatric Neurology, Children's Hospital of Eastern Ontario, and tFaculty of Medicine, University of Ottawa, Ottawa, ON.

Correspondence to: Mr. Rohit Gandhi, 55 Hyannis Avenue, Ottawa, ON K2J 2W9; rohit.gandhi@uottawa.ca.

This article has been peer reviewed.

(C) Canadian Association of Emergency Physicians 
Headaches are a common problem in the pediatric population. In one of the largest pediatric headache population-based studies to date, Bille found that $75 \%$ of 8,993 children had a significant headache before the age of $15 .{ }^{1}$ The spectrum of headache disorders is large, which often makes diagnoses difficult. Headaches are broadly classified as either primary or secondary, with primary headache disorders representing over $90 \%$ of instances. Migraine is the most common type of primary headache in the childhood population. ' Secondary headaches include conditions such as subarachnoid hemorrhage, acute or chronic meningitis, and intracranial hypertension.

Most children who present with headaches in the primary care setting do not have secondary headaches and do not require neuroimaging as part of their workup. ${ }^{3}$ A single cranial computed tomographic (CT) scan delivers 20 to $56 \mathrm{mGy}$ units of radiation to the brain, a radiation dose with significant risks. ${ }^{4} \mathrm{~A}$ recent study demonstrated that a dose of $50 \mathrm{mGy}$ can triple the risk of leukemia and doses of $60 \mathrm{mGy}$ may triple the risk of brain cancer in pediatric patients. ${ }^{5}$ In another study of 680,000 Australians exposed to CT scanning when under the age of 19 , the cancer incidence was increased by $24 \%$ (95\% CI 20-29) over the unexposed population. ${ }^{6}$

In 2002, the American Academy of Neurology (AAN) developed guidelines for investigations in patients 3 to 18 years of age who present with recurrent headache not associated with trauma, fever, or other provocative causes and who have a normal neurologic examination. Level B recommendations from class II and III evidence are that such patients should not undergo neuroimaging. ${ }^{3}$ We suspect that many physicians may be unaware of these guidelines and needlessly exposing patients presenting with primary headaches to harmful radiation by ordering CT scans. Although the rationale for physician is complex and situation specific, it is possible that non-evidence-based factors are influencing decision making.

The primary objective of this study was to determine the frequency of CT scanning ordered by a range of medical practitioners for pediatric patients presenting with primary headache.

The secondary outcomes were the frequency of CT scans categorized by ordering service and year, the proportion of CT scans with significant findings, and the proportion of CT scans that changed diagnosis and management.

\section{MATERIALS AND METHODS}

\section{Study design}

A retrospective medical record review was conducted at the Children's Hospital of Eastern Ontario (CHEO), a pediatric tertiary care centre in Ontario. Approval from CHEO's Research Ethics Board was obtained.

\section{Selection of participants}

Records from 2004 to 2009 were collected for all patients age 2 to 18 referred to the outpatient neurology clinic at CHEO with "headache" or "migraine" as the primary complaint. We derived our patient population from this pool for two reasons: 1) the 2004-2009 time frame provided a sufficient postpublication time for physicians to have become familiar with the 2002 publication of the AAN guidelines for headache evaluation $^{3}$ and 2) a population of patients referred to a neurology outpatient care clinic permitted accuracy and uniformity in the diagnosis of a primary headache. We intended to capture a cohort of primary headache patients who had more "complicated" headaches or a higher incidence of recurrent headaches. The latter rationale was felt to be especially important for this study because this subgroup of primary headache patients, despite unchanging presentations over long intervals of time, are at a higher risk for overinvestigation due to their high frequency of emergency department and family physician visits, coupled with heightened parental and patient anxiety.

In total, 151 charts were randomly selected for review out of a possible 1,076 patient records, using Excel's (Microsoft Corporation, Redmond, WA) random generator functionality. The sample size was predetermined as a result of our using an existing database created for a larger study that investigated the total costs associated with pediatric headache. Power calculations were not performed. The $95 \%$ confidence intervals used to report the data are exact binomial confidence limits derived using the Clopper-Pearson method.

\section{Exclusion criteria}

The exclusion criteria were patients referred to Neurology for reasons other than "headache" or "migraine" as the primary complaint; historical features 
to suggest recent onset of headache, change in type of headache, or associated features of headache that would suggest neurologic dysfunction; first presentation of acute headache; patients admitted to hospital for headaches or seen by Neurology in consultation during an admission; patients receiving a neurologic assessment in consultation in the emergency department; cases that were documented as being discussed over the telephone with a neurologist; or patients with a past history of neurosurgery.

\section{Data collection and processing}

The primary record review was performed independently by two medical students in CHEO's Medical Records Department, and subsequent secondary reviews were conducted concurrently by both students. The site investigator and chief resident trained and supervised the reviewers during the data collection process. Records were reviewed to identify predefined variables from the medical history, physical examination, neurologic assessment, imaging investigations, and management. Chart reviewers followed an explicit chart extraction protocol using an Access database (version 2007; Microsoft Corporation) to independently enter the collected chart data into preformatted database forms. All variables were defined by the authors before the chart abstraction. Physician documentation in emergency department and neurology records were the preferred data source for abstraction, and nursing or clerical documentation was used as a secondary source. Data were extracted and reviewed by site investigators before submission for analysis by an independent CHEO statistician.

\section{RESULTS}

Of the 151 charts reviewed, 99 met our inclusion criteria. Demographic characteristics for the study patients are provided in Table 1. From 2004 to 2009, 34 of 99 patients (34\%; 95\% CI 25-45) received head CT scanning as part of their headache workup.

\section{CT scan findings}

Of the 34 patients imaged, none $(0 \%$; $95 \%$ CI $0-10)$ of the CT scans had any significant findings. Three of the 34 (9\%; 95\% CI 2-24) CT scans had incidental findings: a small focal area of attenuation in left frontal

\begin{tabular}{|c|c|}
\hline Characteristic & $n$ \\
\hline \multicolumn{2}{|l|}{ Patients } \\
\hline Male & 51 \\
\hline Female & 48 \\
\hline Mean age (yr) & 11 \\
\hline Median age (yr) & 11 \\
\hline \multicolumn{2}{|l|}{ Family history } \\
\hline Migraine & 48 \\
\hline Headache & 26 \\
\hline Migraine and headache & 7 \\
\hline \multicolumn{2}{|l|}{ Final diagnosis by neurology } \\
\hline Migraine without aura & 40 \\
\hline Probable migraine & 12 \\
\hline Chronic daily headache & 12 \\
\hline Migraine with aura & 10 \\
\hline Tension type & 9 \\
\hline Other & 8 \\
\hline Secondary to illness & 5 \\
\hline Unclassified & 4 \\
\hline
\end{tabular}

lobe $(n=1)$, nasal polyps of the maxillary sinus $(n=1)$, and a small arachnoid cyst involving peripineal cistern $(n=1)$.

\section{Impact on diagnosis and management}

None of the 34 (0\%; 95\% CI 0-10) CT scans changed the headache diagnosis or management.

\section{CT scans by service and year}

Of the 34 CT scans performed, 11 (32\%) were ordered by neurologists, 15 (44\%) by community physicians, and $8(24 \%)$ by CHEO emergency physicians. Figure 1 shows the distribution of CT scans ordered by year for each service from 2004 to 2009. The most CT scans were ordered in 2008.

\section{DISCUSSION}

\section{Frequency of CT scans}

A number of high-quality adult and pediatric studies have been published that demonstrate a low yield of CT scans in patients with primary headache. ${ }^{3,7}$ A review of 11 studies of adult patients presenting with migraine headaches by the AAN found that the prevalence of significant intracranial abnormalities on neuroimaging 


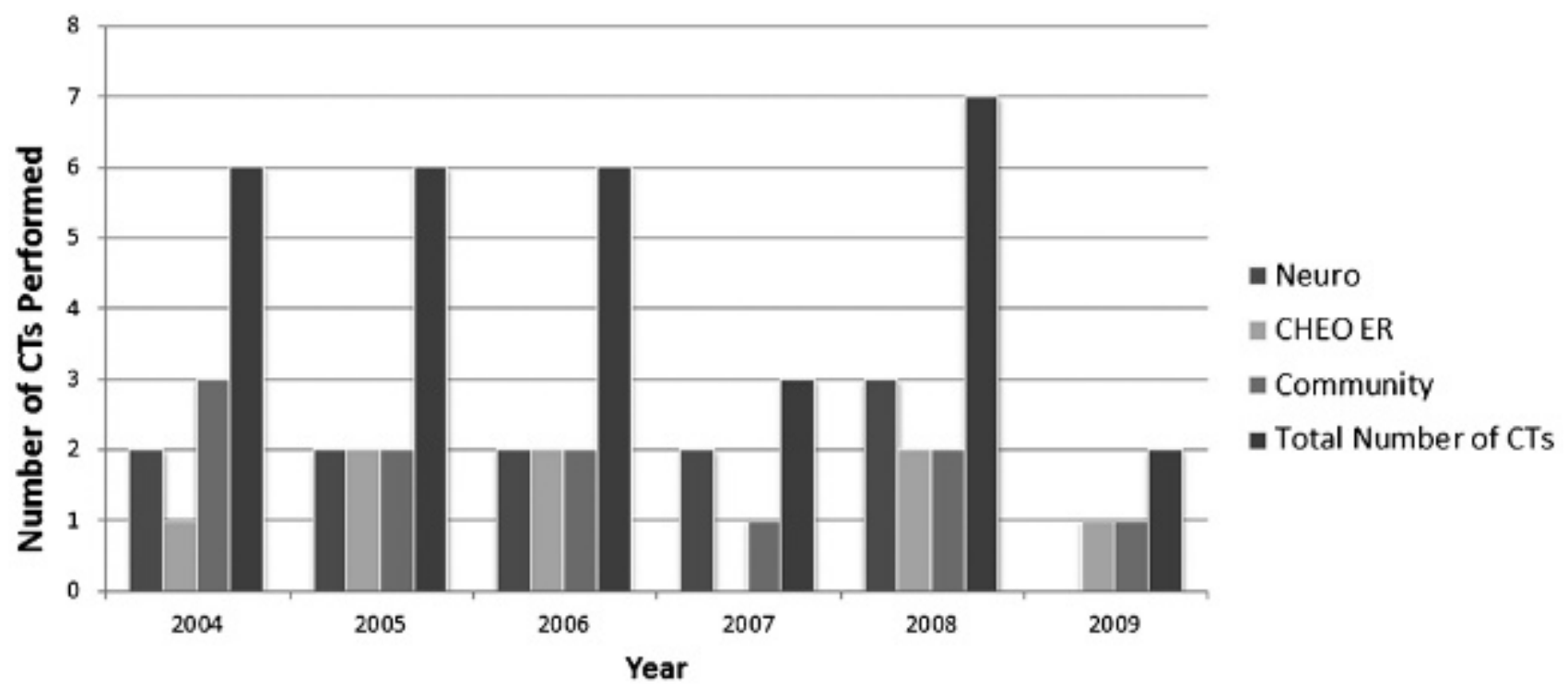

Figure 1. Number of computed tomography scans ordered by physicians. CHEO = Children's Hospital of Eastern Ontario; CTs = computed tomographic scans; ER = emergency room.

ranged from 0 to $3.1 \% .^{7}$ As the majority of adult migraine patients report onset at less than 20 years of age, ${ }^{8}$ this AAN review is an important consideration when making medical decisions regarding the pretest probability of intracranial abnormalities in the pediatric migraine population. Similar findings have been reported in the pediatric literature, as illustrated in a 2008 study of 1,275 children presenting with migraine and a normal neurologic examination in which no significant abnormalities were seen on imaging. ${ }^{9-14}$ Despite the literature showing a vanishingly low pretest probability in the population of interest, our findings indicate that physicians order CT scans in over one-third of pediatric patients presenting with recurrent headaches and a normal neurologic examination. Two recent US studies reached similar conclusions. ${ }^{15,16}$ Despite the lack of randomized controlled trials examining the use of CT scan in pediatric headache patients, the AAN guidelines have used the best available evidence composed of class II and class III studies. These guidelines are considered best practice and were reaffirmed in 2003, 2005, and 2013.

\section{CT scan findings and impact on diagnosis and management}

None of the 34 CT scans performed had significant findings or resulted in change to headache diagnosis or management, a finding in keeping with the literature. ${ }^{17}$
Three scans showed incidental findings, deemed to be unrelated to the cause of the patient's headaches. Children with primary headache and a normal neurologic examination have a $5 \%$ probability of an incidental finding on neuroimaging. ${ }^{3}$ Such incidental findings can further complicate management as they are known to contribute to increased patient stress and anxiety, as well as further testing..$^{18}$ A 2010 study of 206 healthy volunteers undergoing brain imaging found a $19 \%$ rate of incidental findings, with half of these cases undergoing additional imaging. Despite the high number of incidental findings, none of the 206 patients in this study required any specific treatment. ${ }^{19}$ It is clear that neuroimaging is unlikely to show any significant abnormalities in our population of interest, nor is it likely to change patient diagnosis or management.

\section{CT scans by service and year with associated risks}

A similar number of CT scans were ordered among emergency physicians, community physicians, and neurologists. This statistic was surprising to us because we assumed that neurologists and physicians who more commonly see children with headaches would be more familiar with, and more apt to follow, the AAN guidelines on neuroimaging. It appears that, regardless of their specialty, physicians in our study do not adhere to evidence-based imaging guidelines. Although physician rationale is complex and situation specific, 
non-evidence-based factors, such as multiple visits, fear of missing organic pathology, patient or parental angst, or fear of medical-legal consequence, may be driving decisions to perform neuroimaging. A recent survey published in the Archives of Internal Medicine found that $90 \%$ of doctors overtest or overtreat patients due to the fear of being sued for medical malpractice. ${ }^{20}$

The dose of radiation from a single head CT scan carries quantifiable risk to the pediatric population. Children are more sensitive to radiation than adults are, and their longer life expectancy increases their window of opportunity for manifesting long-term sequelae from radiation. When a pediatric patient presents with neurologic signs in addition to headache, the pretest probability of finding an intracranial abnormality significantly increases and their threefold higher risk of developing leukemia from a single CT scan may be acceptable. ${ }^{5}$ When a scan is being performed for reasons that are not evidence based, these risks are arguably unacceptable. Patients meeting the criteria of the AAN guidelines have no indication for imaging, particularly imaging with ionizing radiation. Our study suggests that a significant proportion of primary headache patients are being exposed to the risks of harmful radiation even though the likelihood of finding pathology from neuroimaging is roughly equivalent to the general population. ${ }^{3}$

It would be expected that some lag time would be required for physicians to incorporate the 2002 AAN guidelines into their daily practice. Despite this, no decline in CT scans occurred across all services in our study and the highest number of CT scans performed occurred in 2008, 6 years after the publication of the guidelines.

\section{Experiences from other centres}

Given the demographic diversity of our cohort, it is possible that other centres across Canada have similar rates of CT scan use in children presenting with recurrent headache and normal neurologic examinations. A 2013 study of pediatric headache patients in the United States highlighted similar findings to ours regarding the use of ionizing radiation. ${ }^{21}$ Other Canadian centres should consider initiatives to encourage a greater level of awareness and adherence to guidelines regarding neuroimaging in children with recurrent headaches and a normal neurologic examination.

\section{Limitations}

The retrospective nature of our study makes it vulnerable to environmental and population biases based on the specifics of the population that was selected. We examined the medical decision making of local Ottawa physicians over a specific time period. Although we believe it is reasonable to assume that other Canadian academic and nonacademic centres would have similar rates of compliance with the AAN guidelines, this cannot be certain.

Our sample patient population, drawn from an outpatient neurology clinic, was selected to ensure the uniformity and accuracy of primary headache diagnosis; however, community physicians and emergency physicians undoubtedly see many patients with primary headache who do not receive CT scans. This subset of patients was not studied; thus, our results cannot be generalized to this group. Because our study population was drawn from those referred to a neurologist, we have assumed that our cohort is composed of a higher population of patients with chronic primary headache conditions, resulting in frequent and recurrent visits to family doctors and emergency departments and an increased risk of being overinvestigated. Although such situations can be complex and frustrating for both patients and physicians, adherence to the AAN guidelines should be maintained. In the context of a normal neurologic examination and an unchanging headache, few, if any, such patients require a CT scan. Although medical decision making involves numerous variables on different levels, physicians should fully evaluate the risks and benefits of neuroimaging in such situations before it is pursued.

\section{CONCLUSION}

A high proportion of children presenting with primary headaches and a normal neurologic examination undergo CT scanning, despite well-established AAN guidelines regarding neuroimaging. Most of these CT scans do not appear to alter diagnosis and management. A variety of non-evidence-based factors may be encouraging physicians to overinvestigate this population and, as a result, increasing the risk of adverse events due to radiation exposure. Implementing initiatives at a sitebased level that promote the use of established guidelines before performing CT scans in this population may be beneficial. If physicians feel compelled to 
perform a CT scan outside AAN guidelines, the risks and benefits should be carefully considered. Further studies are needed to examine whether this trend is ongoing and exists elsewhere in Canada.

Acknowledgements: We would like to acknowledge the University of Ottawa Faculty of Medicine and the Departments of Emergency Medicine and Neurology at CHEO.

Competing interests: None declared.

\section{REFERENCES}

1. Bille B. Migraine in school children. Acta Paediatr Suppl 1962;136:1-151.

2. Abu-Arefeh I, Russell G. Prevalence of headache and migraine in schoolchildren. BM7 1994;309:765-9, doi:10. 1136/bmj.309.6957.765.

3. Lewis D, Ashwal S, Dahl G, et al. Practice parameter: evaluation of children and adolescents with recurrent headaches. Neurology 2002;59:490-8, doi:10.1212/WNL.59.4.490.

4. Shrimpton PC, Hillier MC. Doses from computed tomography (CT) examinations in the UK. National Radiological Protection Board 2005;67:W67.

5. Pearce M, Salotti J, Little M, et al. Radiation exposure from CT scans in childhood and subsequent risk of leukaemia and brain tumours: a retrospective cohort study. Lancet 2012;380: 499-505, doi:10.1016/S0140-6736(12)60815-0.

6. Mathews J, Forsythe A, Brady Z, et al. Cancer risk in 680000 people exposed to computed tomography scans in childhood or adolescence: data linkage study of 11 million Australians. BM7 2013;346:f2360, doi:10.1136/bmj.f2360.

7. Frishberg B, Rosenberg J, Matchar D, et al. Evidence-based guidelines in the primary care setting: neuroimaging in patients with nonacute headache. Minneapolis: American Academy of Neurology; 2000. p. 1-25.

8. Babineau SE, Green MW. Headaches in children. Continuum (Minneap Minn) 2012;18:853-68.

9. Maytal J, Bienkowski R, Patel M, et al. The value of brain imaging in children with headaches. Pediatrics 1995;96:413-6.
10. Medina L, Pinter J, Zurakowski D, et al. Children with headache: clinical predictors of the surgical space-occupying lesions and the role of neuroimaging. Radiology 1997;202: 819-24.

11. Dooley J, Camfield P, O'Neill M, et al. The value of CT scans for children with headaches. Can $\mathcal{F}$ Neurol Sci 1990;17: 309-10.

12. Wober-Bingol C, Wober C, Prayer D, et al. Magnetic resonance imaging for recurrent headache in childhood and adolescence. Headache 1996;36:83-90, doi:10.1046/j.15264610.1996.3602083.x.

13. Chu M, Shinnar S. Headaches in children younger than 7 years of age. Arch Neurol 1992;49:79-82, doi:10.1001/ archneur.1992.00530250083020.

14. Lewis D, Dorbad D. The utility of neuroimaging in the evaluation of children with migraine or chronic daily headache who have normal neurologic examinations. Headache 2000;40:29-632.

15. DeVries A, Young P, Wall E, et al. CT scan utilization patterns in pediatric patients with recurrent headache. Pediatrics 2013;132:e1-8, doi:10.1542/peds.2012-3862.

16. Rho Y, Chung H, Suh E, et al. The role of neuroimaging in children and adolescents with recurrent headaches - multicenter study. Headache 2011;51:3:403-8, doi:10.1111/j.1526-4610. 2011.01845.x.

17. Graf W, Kayyali H, Abdelmoity A, et al. Incidental neuroimaging findings in nonacute headache. 7 Child Neurol 2010;25:1182-7, doi:10.1177/0883073809353149.

18. Lumbreras B, Donat L. Incidental findings in imaging diagnostic tests: a systematic review. Br F Radiol 2010;83:27689, doi:10.1259/bjr/98067945.

19. Hartwigsen G, Siebner H, Deuschl G, et al. Incidental findings are frequent in young healthy individuals undergoing magnetic resonance imaging in brain research imaging studies: a prospective single-center study. 7 Comput Assist Tomogr 2010; 34:596-600, doi:10.1097/RCT.0b013e3181d9c2bb.

20. Bishop T, Federman A, Keyhani S. Physicians' views on defensive medicine: a national survey. Arch Intern Med 2009; 170:1081-3.

21. Sheridan D, Meckler G, Spiro D, et al. Diagnostic testing and treatment of pediatric headache in the emergency department. 7 Pediatr 2013;163:1634-7, doi:10.1016/j.jpeds. 2013.07.006. 